\title{
Low Dose, Low Cost Estradiol Pellets Can Support MCF-7 Tumour Growth in Nude Mice without Bladder Symptoms
}

\author{
Genevieve Dall1 ${ }^{1}$, Jessica Vieusseux², Ashleigh Unsworth², Robin Anderson²,3 and Kara Britt2,3凶 \\ 1. Prostate Cancer Laboratory, Department of Anatomy and Developmental Biology, Monash University Clayton, Australia \\ 2. Metastasis Laboratory, Peter MacCallum Cancer Centre, 7 St Andrew's Place, East Melbourne, Australia \\ 3. The Sir Peter MacCallum Department of Oncology, University of Melbourne, Parkville, Australia \\ $\triangle$ Corresponding author: kara.britt@petermac.org
}

() 2015 Ivyspring International Publisher. Reproduction is permitted for personal, noncommercial use, provided that the article is in whole, unmodified, and properly cited. See http://ivyspring.com/terms for terms and conditions.

Received: 2014.10.23; Accepted: 2015.09.25; Published: 2015.10.29

\begin{abstract}
MCF-7 cells are a slow growing estrogen receptor (ER) positive human breast cancer cell line that is commonly used to model estrogen responsive breast cancer cell growth in-vitro and tumour growth in-vivo. These tumours require estrogen supplementation, and in-vivo doses of between $0.72 \mathrm{mg}$ and $2 \mathrm{mg}$ estradiol pellets are commonly implanted in the dorsal flank of ovariectomised, immunocompromised mice. We wanted to grow MCF-7 tumours in immunocompromised mice without the need to be ovariectomised. When we treated immunocompromised mice with $0.72 \mathrm{mg}$ pellets to induce MCF7 tumour growth, the mice developed urosepsis. We have now shown that lower doses of estradiol pellets, $0.3 \mathrm{mg}$ and $0.5 \mathrm{mg}$, induce elevated serum estrogen levels and maintain tumour growth, without causing urosepsis. Supplementation for only one week did not support sustained MCF7 tumour growth. In conclusion, $0.3 \mathrm{mg}$ and $0.5 \mathrm{mg}$ silastic pellets can be used to stimulate ER+ breast cancer growth in ovary-intact, immune compromised mice.
\end{abstract}

Key words: MCF-7 cells, estrogen, urosepsis, breast cancer

\section{Introduction}

The MCF-7 cell line is a breast cancer cell line isolated in 1970 from the pleural effusion of a 69-year-old Caucasian woman [1]. These cells express estrogen receptor (ER) and are one of only a few human breast cancer cell lines that are estrogen dependent $[2,3]$. Estrogen supplementation is required to stimulate their growth and $0.72-2 \mathrm{mg}$ subcutaneous pellets are routinely given, predominantly in ovariectomised mice. We wanted to grow MCF-7 tumours in mice without ovariectomy prior to tumour injection and estrogen supplementation. Published data indicate that slow release pellets (from Innovative Research America, Sarasota, FL; IRA) at a dose of $0.72 \mathrm{mg}$ will achieve $300-400 \mathrm{pg} / \mathrm{ml}$ plasma estradiol levels that are comparable to levels in women in the middle of their menstrual cycle. The $1.7 \mathrm{mg}$ pellets achieve $700-900 \mathrm{pg} / \mathrm{ml}$ that is equivalent to the highest peak in pre-menopausal women the day prior to the $\mathrm{LH}$ peak. Because of this the $0.72 \mathrm{mg}$ pellets are commonly used to support the growth of MCF-7 cells in nude mice $[4,5]$ and $1.7 \mathrm{mg}$ pellets in other studies $[6,7]$.

In non-ovariectomised immune comprosmied NOD SCID mice, we attempted to grow MCF-7 tumours using supplementation with the lower dose of $0.72 \mathrm{mg} 60$ day release estradiol pellets from IRA. The bladder is vulnerable to the adverse effects of drugs because of its complex control and the frequent excretion of drug metabolites in the urine. Incontinence results when bladder pressure exceeds sphincter resistance. We found that slow release $0.72 \mathrm{mg}$ estradiol pellets led to severe urine retention in the bladder, with uni- or bilateral hydronephrosis in the mice. These adverse effects have been observed in previous studies, but with much larger doses of estrogen $(1.72 \mathrm{mg})$ [8-10]. Here we show that silastic implants generated in our laboratory with low dose estradiol 
(0.3mg and $0.5 \mathrm{mg}$ ) can support MCF-7 cell growth without the adverse urinary tract effects noted with higher doses. Anecdotally, MCF-7 cells are said to only need a pulse of estrogen in the first few days of growth, and then can be maintained without further supplementation. To test this we also included a set of mice that were treated for only 7 days. Our results reveal that low cost, low dose silastic implants of estradiol can be used effectively in immunocompromised mice to support the growth of MCF-7 tumours without adverse urinary effects.

\section{Materials and Methods}

\section{Animals}

All animal work was completed under Monash University Animal Ethics Committee approval or Peter MacCallum Cancer Centre Animal Ethics Committee approval. Female NOD SCID and nude mice were purchased from ARC and used at 8-10 weeks of age. They were housed in microisolator cages provided with antibiotic water (Enrotril) as per manufacturer's instructions.

\section{Estrogen pellets}

NOD SCID mice were supplemented with 60day $0.72 \mathrm{mg}$ slow release estradiol pellets purchased from Innovative Research of America (IRA), Sarasota, FL. For the lower estrogen doses, silastic estrogen pellets $(0.3 \mathrm{mg}$ or $0.5 \mathrm{mg})$ were prepared as described previously [11] and implanted into NOD SCID or nude mice. All pellets were implanted subcutaneously into the dorsal flank.

\section{Estradiol radioimmunoassay (RIA)}

To confirm that the silicone estradiol pellets were increasing plasma estradiol levels, plasma (50ul) was assayed using reagents from the DSL ultra-sensitive 125I-estradiol RIA kit (DSL-4800, Diagnostics Systems Laboratories, Webster, TX). The procedure was modified slightly by addition of 50ul charcoal stripped mouse serum to estradiol standards prepared from crystalline 17-beta estradiol (Sigma, Saint Louis, $\mathrm{MO}$; Cat \#E-8875). The lower limit of detection was $3.9 \mathrm{pg} / \mathrm{mL}$, and the within-assay coefficient of variation was $11.4 \%$. All assays were completed on plasma samples taken at the end of the experiment.

\section{Tumor inoculation}

MCF-7 cells were grown in DMEM $+10 \% \mathrm{FBS}, \quad 1 \%$ penicillin/streptomycin, $10 \mathrm{ug} / \mathrm{ml}$ insulin. Cells in PBS $\left(1 \times 10^{6}\right)$ were injected into the 4th mammary fat pad of immune compromised mice in a 1:1 ratio with growth factor reduced Matrigel (In Vitro Technologies). Tumor growth was monitored over time using electronic calipers. The greatest longitudinal diameter (length) and the greatest transverse diameter (width) were measured. Tumor volumes were estimated by the modified ellipsoidal formula: volume $=1 / 2$ (length $x$ width $^{2}$ ) [12]. Mice were culled when the tumors reached ethical limits.

\section{Results}

\section{High dose estrogen supplementation in ovary intact mice leads to urinary tract complica- tions}

Whilst mice supplemented with $0.72 \mathrm{mg}$ estradiol pellets sustained growth of MCF7 tumors in-vivo (Figure 1a), 13/30 mice developed severe urine retention, hardened bladders and peri-anal ulcers. Palpation of bladders did not relieve the symptoms and five mice deteriorated, lost weight and were culled for humane reasons. Upon autopsy, these mice exhibited increased kidney size, in some cases pale kidney colour, and most distinctly crystallized urine within the bladder (Figure 1b).
A

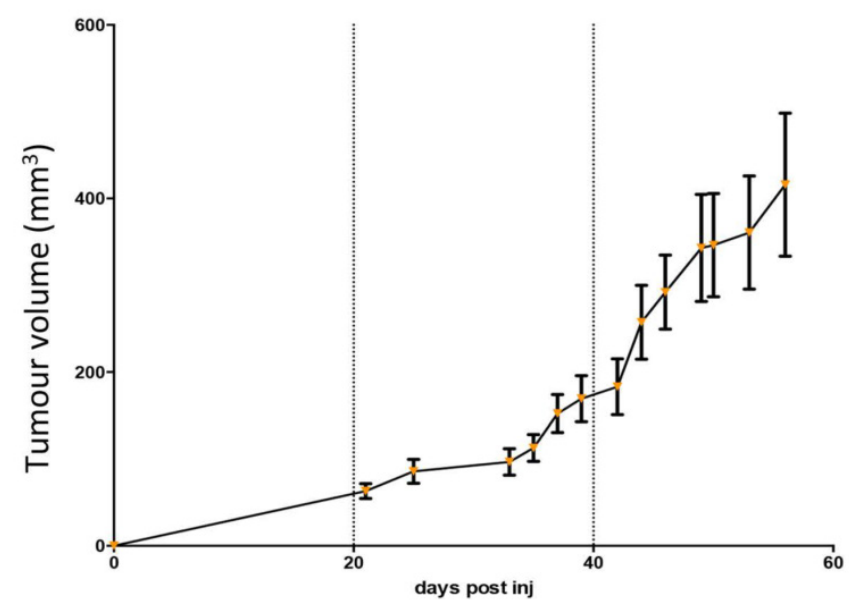

B

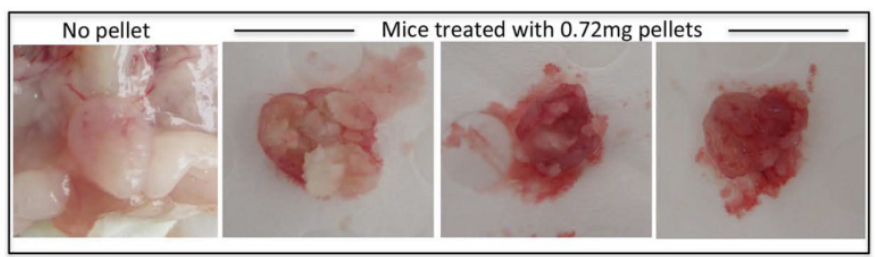

Figure 1: High dose estrogen stimulates MCF7 tumour growth but leads to crystalized bladders. (A) MCF7 tumour growth over time in NOD SCID mice supplemented with $0.72 \mathrm{mg}$ estradiol pellets. Data is presented as mean+/- SEM. (B) The crytalised bladders of 3 mice treated with $0.72 \mathrm{mg}$ estradiol pellets and a representative healthy bladder from a mouse with no estrogen supplementation. 


\section{Low dose estrogen supplementation stimu- lates growth of MCF7 cells without urinary tract complications.}

Chronic supplementation with either $0.3 \mathrm{mg}$ or $0.5 \mathrm{mg}$ estradiol sustained MCF7 tumour growth in nude mice (Figure 2a) and achieved plasma estradiol levels similar to those observed in ovariectomised mice given $0.72 \mathrm{mg}$ pellets. Mice supplemented for one week only initially grew tumours (Figure 2a) but this growth was not sustained and plasma estradiol levels at the end of the experiment were not increased. We did not show the BALB/c nude mice tumour growth over time in Figure 2a as is was performed in a separate experiment and so cannot be directly compared. It is included in the results for plasma and organ weights for comparison. Tumour weights varied within the groups, as shown with the final tumour weights (Figure $2 b$ ), however as we only used $n=4$ mice per group, this was not surprising. The plasma estradiol levels were similar in mice without an estrogen pellet, or if supplemented for only one week (Figure 2c). Plasma estradiol was significantly increased in mice with chronic estrogen supplementation of $0.3 \mathrm{mg}$ and $0.5 \mathrm{mg}$ to approximately $500 \mathrm{pg} / \mathrm{ml}$. Plasma estradiol levels were lower than those measured in mice bearing $0.72 \mathrm{mg}$ pellets, approximately $1000 \mathrm{pg} / \mathrm{ml}$ (Figure 2c). Uterine weights were increased in the $0.3 \mathrm{mg}$ and $0.5 \mathrm{mg}$ groups, but only after chronic administration (Figure 2d). Neither the $0.3 \mathrm{mg}$ or $0.5 \mathrm{mg}$ chronic supplementation led to urosepsis, symptoms of urinary infections nor other signs of ill health. At autopsy all mice appeared healthy with estrogenized uteri (Figure 2d) and no visible hydronephrosis (Figure 2e). The histology of the kidney and bladder of mice with $0.3 \mathrm{mg}$ pellets appears normal, compared to those that had urosepsis in the $0.72 \mathrm{mg}$ group, where there was abundant immune cell infiltration indicative of inflammation (Figure 3).

To determine if MCF7 tumors would also grow in NOD SCID mice with low dose estrogen supplementation we next tested the $0.3 \mathrm{mg}$ pellets in NOD SCID mice bearing MCF7 tumors. Final tumor weight, plasma estradiol and uterine weights were not significantly different to the weights measured in nude mice (Figure 4).

A final experiment using a larger number of nude mice ( $n=10-12$ per group) reduced the impact of individual variation in tumor size when the mice were supplemented with $0.3 \mathrm{mg}$ estradiol pellets for the entirety of the experiment. There were no signs of estrogen toxicity (Figure 5).

\section{Discussion}

MCF7 cells are an estrogen sensitive human breast cancer cell line commonly used to model ER+ breast cancer, which accounts for $70 \%$ of all breast cancer diagnoses [13]. We wanted to develop a model of MCF7 tumor growth in ovary-intact mice. We initially provided intact mice with $0.72 \mathrm{mg}$ estradiol pellets to stimulate the growth of the MCF7 cells and found that whilst this supported cancer cell growth, $43 \%$ of the mice developed urosepsis. This was first evident as urine stained fur around the genital region, followed by signs of ill health (reduced movement and ruffled fur), with some having distended bladders, leading to early termination of the experiment.

To reduce cost and to reduce the adverse side effects of estrogen supplementation, we decided to generate our own silastic estradiol pellets as described previously [11]. We made our pellets at two doses (0.3mg and $0.5 \mathrm{mg}$ ), that were both lower than the original dose of $0.72 \mathrm{mg}$, which caused the urinary complications. As we had heard anecdotally that MCF7 cells required estrogen supplementation for only a few days to allow tumours to establish, we also tested whether estrogen supplementation for only one week would permit MCF7 tumor growth. All mice were implanted with silastic pellets on the day of MCF7 cell injection and tumour growth was monitored over time. We found that the lower doses could support the development of MCF7 tumours in mice without ovariectomy, and did so without causing urinary tracts complications. In plasma estradiol assays, we confirmed that both of the low dose regimes led to serum estrogen levels that were comparable to the $0.72 \mathrm{mg}$ dose ovarectomised mice, and lower than in intact mice with $0.72 \mathrm{mg}$ pellets. To confirm that the lower dose of estrogen supplementation could be used in NOD SCID mice as well we supplemented a set of NOD SCID mice with $0.3 \mathrm{mg}$ pellets and obtained similar results with no evidence of urosepsis.

Our data showing that high dose estrogen supplementation can lead to renal problems and bladder stone formation in NOD SCID mice is similar to the findings reported previously by Kang and colleagues in BALB/c nude mice [14]. They found that if they reduced the E2 dose from $1.72 \mathrm{mg}$ to $0.18 \mathrm{mg}$ they could still maintain growth of the MCF7 tumours whilst doubling the survival of mice. However there are some unique differences, largely due to the fact we have used ovary intact mice, and their experiments were conducted in ovariectomised mice. We found that the use of $0.72 \mathrm{mg}$ pellets in intact mice gave plasma estradiol levels over $1000 \mathrm{pg} / \mathrm{ml}$, which is double the level that they reported in ovariectomised mice with $1.72 \mathrm{mg}$ pellets. Kang and colleagues reported that high dose estrogen led to a high incidence of mortality and that lower dose pellets $(0.18 \mathrm{mg}$, $0.36 \mathrm{mg}$ and $0.72 \mathrm{mg}$ ) abrogated this [14]. However, even with the use of $0.18 \mathrm{mg}$ pellets, they still observed 
some mortality. In our experiments, no mice were lost using the $0.3 \mathrm{mg}$ or $0.5 \mathrm{mg}$ estrogen pellets and we did not observe any detrimental effects of estrogen on the renal system.
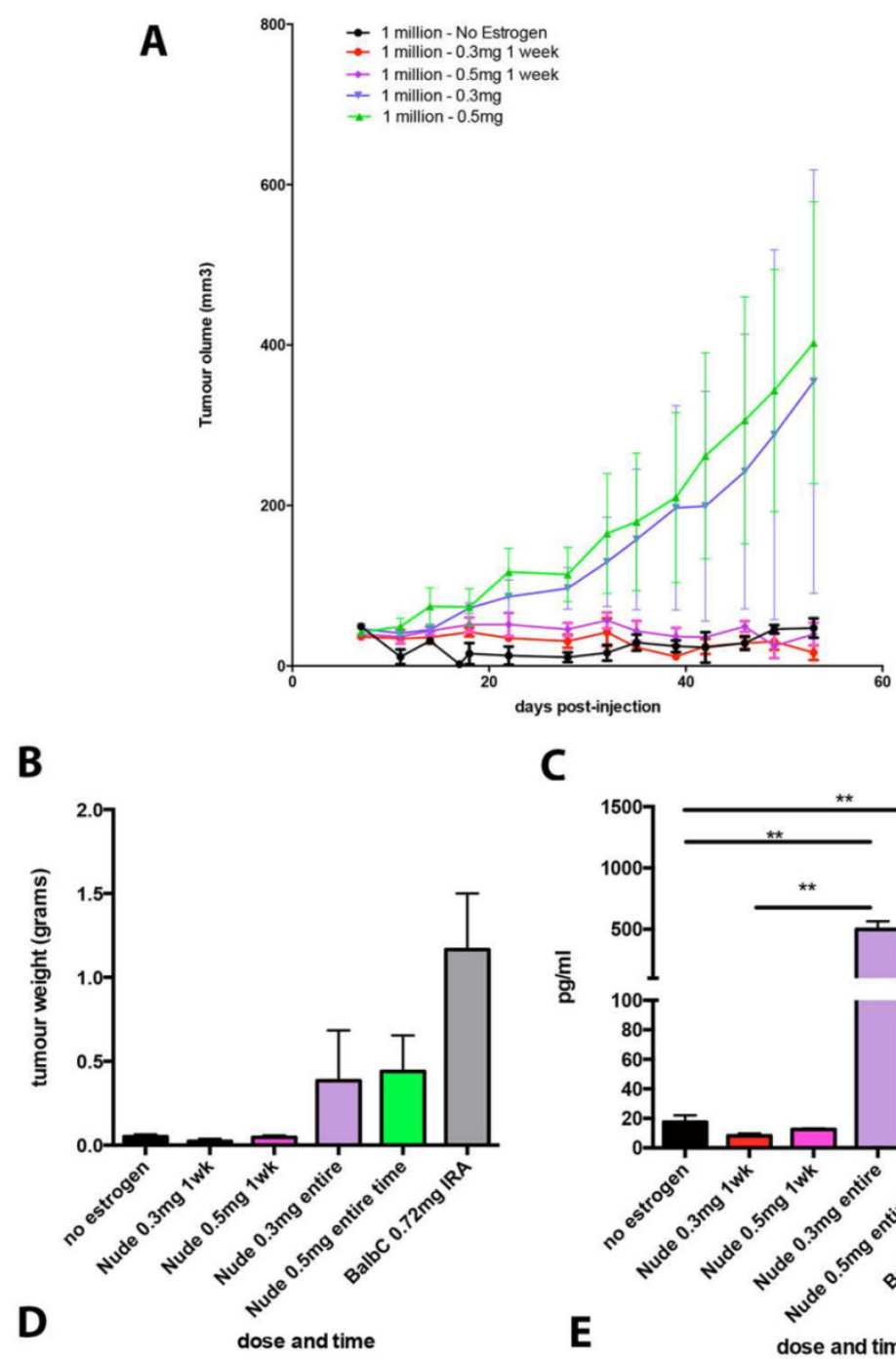

C
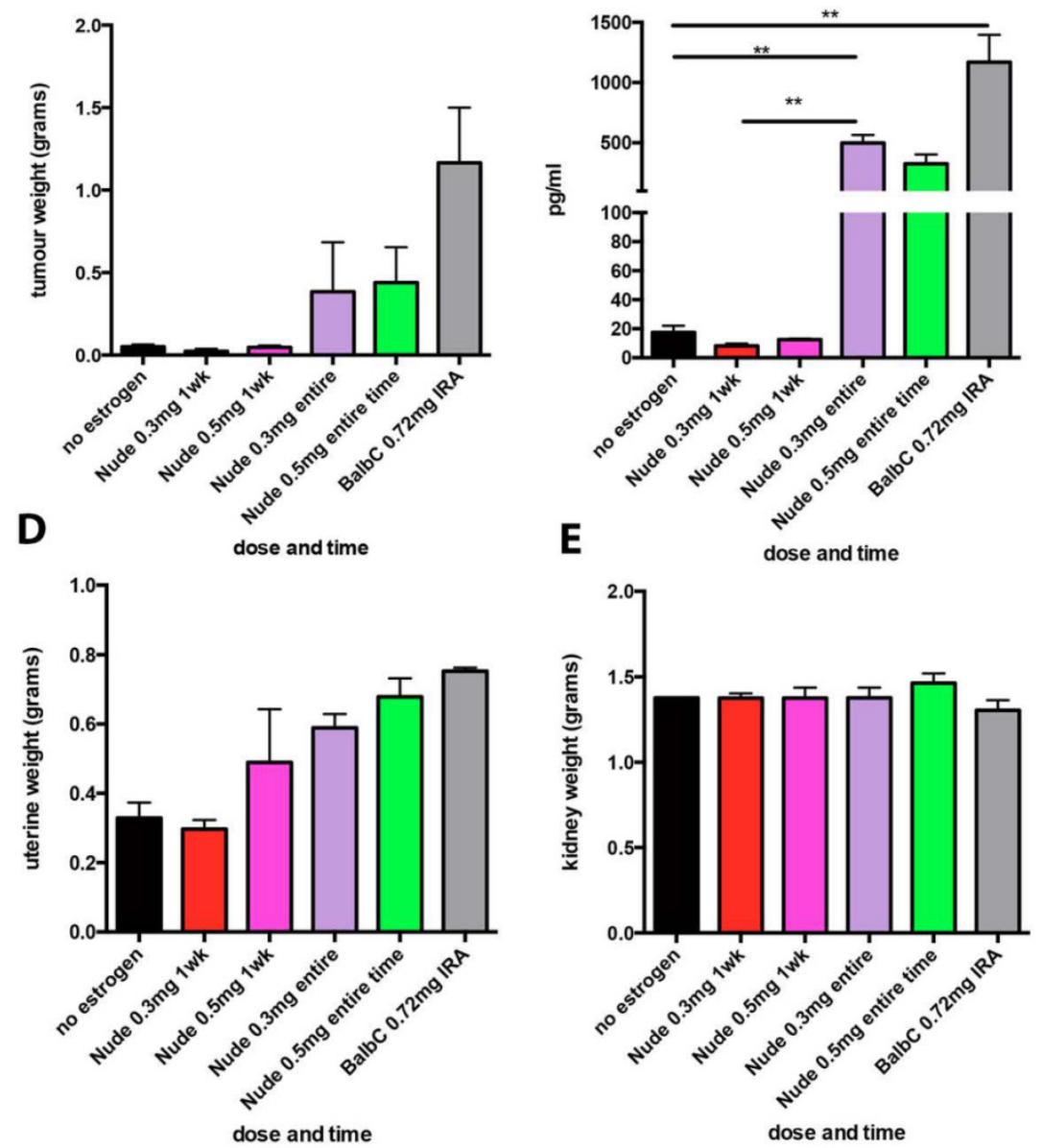

Figure 2: Lower dose estrogen pellets stimulate MCF7 tumour growth in nude mice without urinary symptoms. (A) MCF7 tumour growth over time. (B) End stage tumour weights. (C) Serum estradiol. (D) Uterine weights and (E) Kidney weights in mice implanted with MCF7 cells and supplemented with either no estradiol pellet, $0.3 \mathrm{mg}$ or $0.5 \mathrm{mg}$ estradiol pellets for 1 week only or for the entire experiment ( $n=4$ mice/group). Data on BALB/c mice supplemented with $0.72 \mathrm{mg}$ pellets is included for comparison. Data are presented as mean+/- SEM. Asterix denotes significance $p<0.001$. 


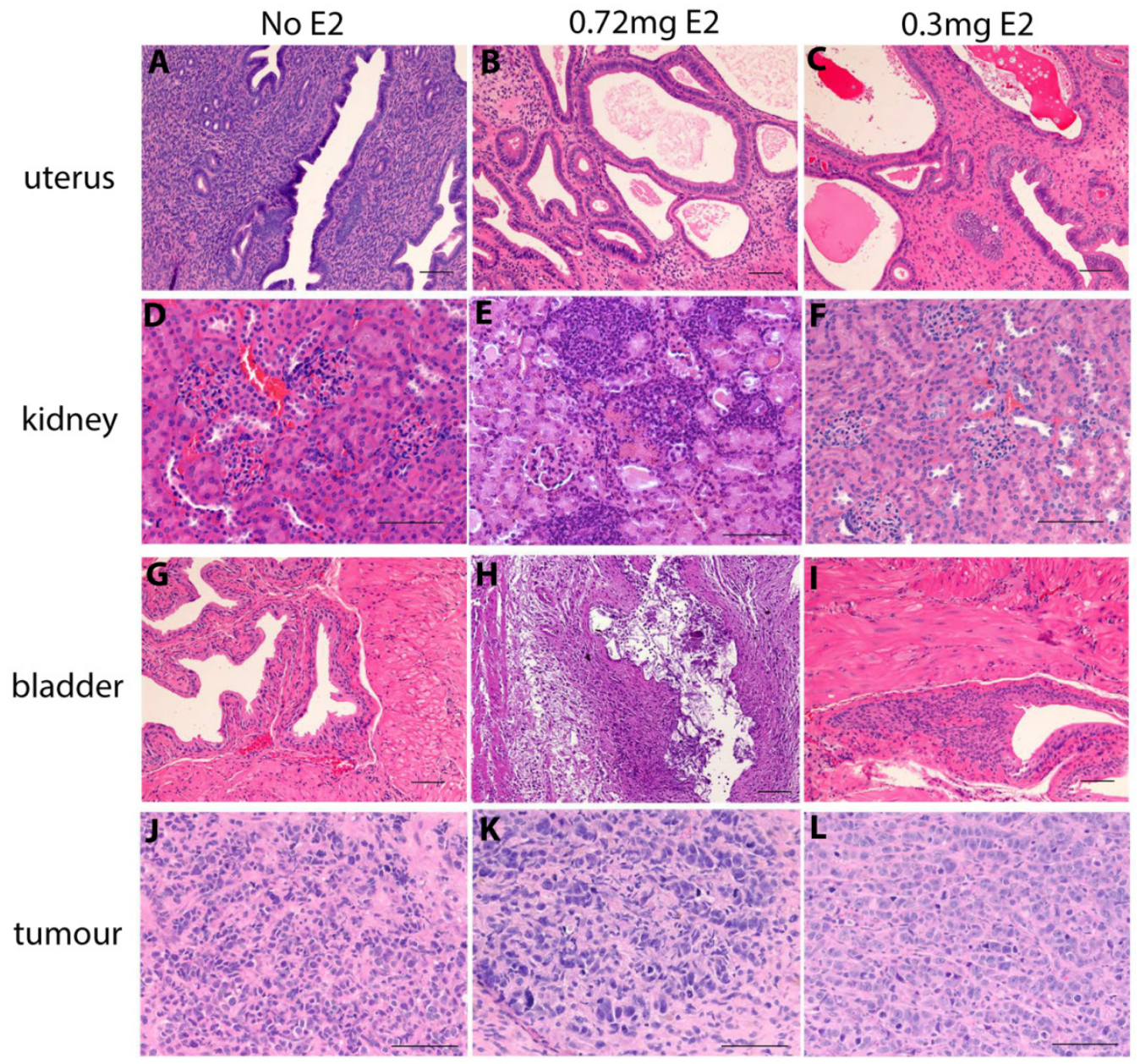

Figure 3: Histology of uterus, bladder, kidney and tumours in estrogen supplemented nude mice. The uterus uterus, kidney, bladder and MCF7 tumor of untreated mice $(\mathrm{A}, \mathrm{D}, \mathrm{G}, \mathrm{J})$ mice treated with $0.72 \mathrm{mg}$ pellets $(\mathrm{B}, \mathrm{E}, \mathrm{H}, \mathrm{K})$ and mice treated with $0.3 \mathrm{mg}$ pellets $(\mathrm{C}, \mathrm{F}, \mathrm{I}, \mathrm{L})$. Scale bars represent 100um

A

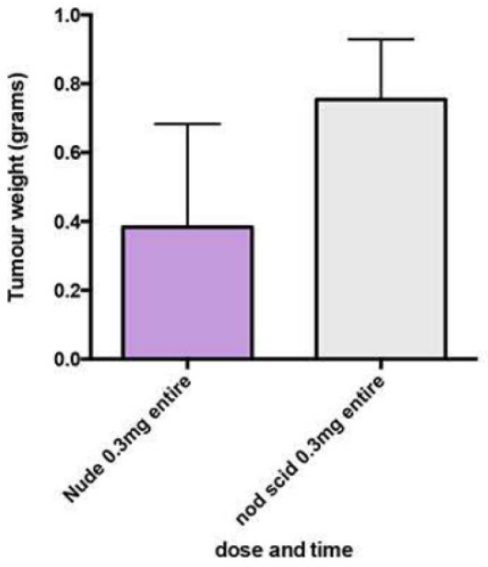

B

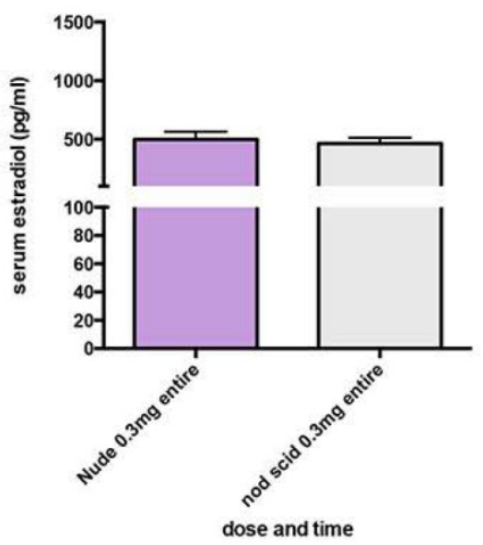

C

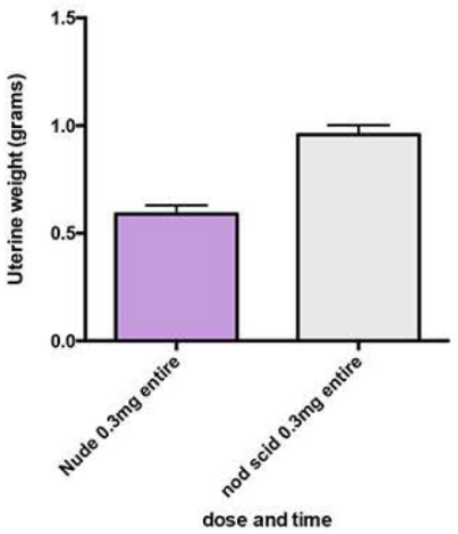

Figure 4: MCF7 tumours in NOD SCID and nude mice respond similarly to estrogen supplementation. (A) End stage tumour weights. (B) serum estradiol and (C) uterine weights in nude mice (purple) and NOD SCID mice (grey) both supplemented with $0.3 \mathrm{mg}$ estrogen pellets. 


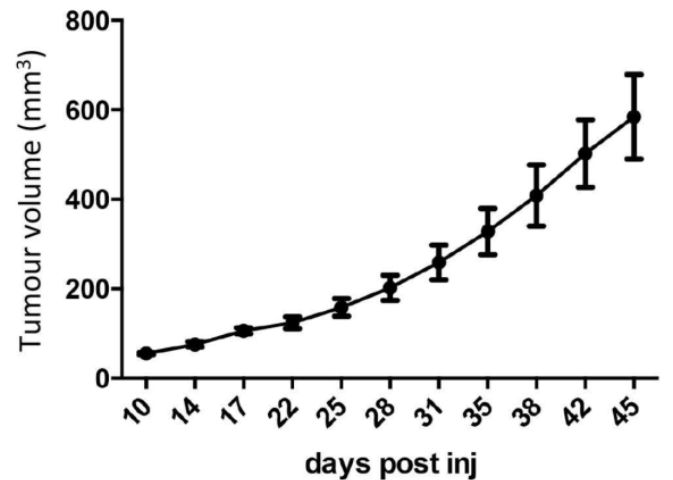

Figure 5: Low dose estrogen consistently sustains MCF7 tumour growth. MCF7 tumour growth over time in nude mice implanted with MCF7 cells in the mammary fat pad and supplemented with $0.3 \mathrm{mg}$ estradiol pellets $(n=11)$.

Our results have important implications for breast cancer researchers using patient derived breast cancer xenografts (PDXs). Exogenous estrogen stimulates growth of breast cancer PDXs and is critical for engraftment. Estrogen improves the take rates of ER positive tumors in immunocompromised mice from $2.4 \%$ (no estrogen) to $25 \%$ (with estrogen) [15]. The Jackson Laboratory states on their website that the NOD SCID gamma (NSG) mice, which are the most immunodeficient and favored in PDX models, are more resistant to the toxic side effects of estradiol supplementation compared to other strains, including nude and NOD-SCID. Thus we propose that the use of low dose pellets will have important implications for these researchers.

In conclusion we report a low cost, low dose estradiol pellet that can be used to support the growth of MCF7 tumor in immune compromised mice over periods of 6 weeks, without urinary tract complications such as bladder stone formation.

\section{Acknowledgements}

We thank the animal facility at Peter MacCallum Cancer Centre for their assistance. GD and AU are supported by Australian Postgraduate Scholarships, RA was supported by National Breast Cancer Foundation of Australia Fellowship. KB was supported by a National Breast Cancer Foundation of Australia Fellowship, a VCA early career seeds grant and an NHMRC new investigator grant.

\section{Competing Interests}

The authors have declared that no competing interest exists.

\section{References}

1. Soule HD, Vazguez J, Long A, Albert S, Brennan M. A human cell line from a pleural effusion derived from a breast carcinoma. Journal of the National Cancer Institute. 1973; 51: 1409-16.

2. Lippman M, Bolan G, Huff K. The effects of estrogens and antiestrogens on hormone-responsive human breast cancer in long-term tissue culture. Cancer research. 1976; 36: 4595-601.
3. Lippman M, Monaco ME, Bolan G. Effects of estrone, estradiol, and estriol on hormone-responsive human breast cancer in long-term tissue culture. Cancer research. 1977; 37: 1901-7.

4. Horii Y, Takei H, Koibuchi Y, Horiguchi J, Maemura M, Iino Y, et al. The regulatory effect of tamoxifen on fibronectin expression in estrogen-dependent MCF-7 breast carcinoma cells. Oncology reports. 2006; 15: 1191-5.

5. Liu Y, el-Ashry D, Chen D, Ding IY, Kern FG. MCF-7 breast cancer cells overexpressing transfected c-erbB-2 have an in vitro growth advantage in estrogen-depleted conditions and reduced estrogen-dependence and tamoxifen-sensitivity in vivo. Breast cancer research and treatment. 1995; 34: 97-117.

6. Gottardis MM, Robinson SP, Jordan VC. Estradiol-stimulated growth of MCF-7 tumors implanted in athymic mice: a model to study the tumoristatic action of tamoxifen. Journal of steroid biochemistry. 1988; 30: 311-4.

7. Hsieh CY, Santell RC, Haslam SZ, Helferich WG. Estrogenic effects of genistein on the growth of estrogen receptor-positive human breast cancer (MCF-7) cells in vitro and in vivo. Cancer research. 1998; 58: 3833-8.

8. Chew GL, Huo CW, Huang D, Blick T, Hill P, Cawson J, et al. Effects of Tamoxifen and oestrogen on histology and radiographic density in high and low mammographic density human breast tissues maintained in murine tissue engineering chambers. Breast cancer research and treatment. 2014; 148: 303-14. doi:10.1007/s10549-014-3169-2.

9. Gakhar G, Wight-Carter M, Andrews G, Olson S, Nguyen TA. Hydronephrosis and urine retention in estrogen-implanted athymic nude mice. Veterinary pathology. 2009; 46: 505-8. doi:10.1354/vp.08-VP-0180-N-BC.

10. Pearse G, Frith J, Randall KJ, Klinowska T. Urinary retention and cystitis associated with subcutaneous estradiol pellets in female nude mice. Toxicologic pathology. 2009; 37: 227-34. doi:10.1177/0192623308329281.

11. Laidlaw IJ, Clarke RB, Howell A, Owen AW, Potten CS, Anderson E. The proliferation of normal human breast tissue implanted into athymic nude mice is stimulated by estrogen but not progesterone. Endocrinology. 1995; 136: 164-71. doi:10.1210/endo.136.1.7828527.

12. Tomayko MM, Reynolds CP. Determination of subcutaneous tumor size in athymic (nude) mice. Cancer chemotherapy and pharmacology. 1989; 24: 148-54.

13. Masood S. Estrogen and progesterone receptors in cytology: a comprehensive review. Diagnostic cytopathology. 1992; 8: 475-91.

14. Kang JS, Kang MR, Han SB, Yoon WK, Kim JH, Lee TC, et al. Low dose estrogen supplementation reduces mortality of mice in estrogen-dependent human tumor xenograft model. Biological \& pharmaceutical bulletin. 2009; 32: $150-2$.

15. Zhang X, Claerhout S, Prat A, Dobrolecki LE, Petrovic I, Lai Q, et al. A renewable tissue resource of phenotypically stable, biologically and ethnically diverse, patient-derived human breast cancer xenograft models. Cancer research. 2013; 73: 4885-97. doi:10.1158/0008-5472.CAN-12-4081. 